\title{
The case for a student run clinic in London
}

Yara Abou-Hamde, Adam Hopfgartner

\section{ABSTRACT}

Student Run Clinics (SRCs) are an emerging form of primary healthcare involving the collaboration of students and licensed health care professionals. SRCs aim to identify healthcare needs in the community and to meet those needs with supervised clinical and non-clinical services, education, and outreach. The SRC model provides students with direct patient interaction to complement classroom learning and develop extracurricular clinical skills.

The Alliance of Students Providing Interprofessional Resources and Education (ASPIRE) is a new interdisciplinary student group from the University of Western Ontario, Fanshawe College, and the University of Waterloo. Using established Canadian SRCs as a framework, ASPIRE is working to start a London-based SRC. A recent review of healthcare needs and social determinants of health completed by ASPIRE for the City of London identified a high incidence of mental health conditions and HIV in the community. Furthermore, the adequate provision of primary healthcare in London is complicated by transportation issues, financial constraints, and language barriers among underserved and minority populations. These concerns may be addressed by care provided by professional students from various disciplines organized by ASPIRE.

The future of ASPIRE includes health promotion in the London community with presentations on topics such as opioid addiction and overdose prevention, diabetic foot care, and smoking cessation. ASPIRE will continue to work towards a transition into a larger role in health promotion and health advocacy, with the ultimate goal of establishing an SRC in the City of London.

\section{INTRODUCTION}

Student run clinics (SRCs) are models of healthcare delivery where students assume a leadership role in the provision of care under the supervision of licensed healthcare professionals. These clinics aim to fill gaps in the healthcare needs of their local communities; for example, they may operate for extended hours, or involve a team of interprofessional students in the care of complex patients. Moreover, SRCs benefit student volunteers by exposing them to clinical encounters, health promotion, and interprofessional work prior to graduation. Today, there are more than seven SRCs in operation across Canada. According to Holmqvist et al, Canadian SRCs place a common emphasis on health equity, interprofessionalism, and student leadership. ${ }^{1}$

\section{CANADIAN SRC EXAMPLES AND SERVICES PROVIDED}

The first SRC became operational in Canada in the year 2000, and involved students at the University of British Columbia. Today, the Community Health Initiative by University Students (CHIUS) is an interdisciplinary student and resident-led team that has partnerships with both the Vancouver Native Health Clinic and Three Bridge Clinic. ${ }^{2}$ At the Three Bridge Clinic, chronic pain management is a core topic that students discuss with their patients. At the Vancouver Native Health Clinic, medical and nursing students provide services that focus on such topics as mental health concerns and chronic disease. These include taking health histories, performing physical exams, and creating personalized care plans.

One of the most successful SRCs in Canada is run by the Student Wellness Initiative Toward Community Health (SWITCH) in Saskatoon, Saskatchewan. SWITCH operates out of the Westside Community Clinic. ${ }^{3}$ Services offered include speech language pathology, physical therapy, occupational therapy, and cultural supports. The clinic also offers nutrition advice, assistance with transportation, and homework help.

In Ontario, there is currently one SRC that is fully operational. The Interprofessional Medical and Allied Groups for Improving Neighbourhood Environment (IMAGINE) clinic is based in Toronto. ${ }^{4}$ Patient identification and OHIP cards are not required to access care at this clinic. Services provided by IMAGINE include the treatment of acute conditions such as infections and wounds, preventative strategies, physiotherapy exercises, medication management, and counselling regarding harm reduction and social work issues. The drop-in clinic operates on Saturdays from 10 am to $2 \mathrm{pm}$.

A number of other SRCs across Canada provide similar services in their local communities, including ones in Regina, Edmonton, Calgary, Winnipeg, Halifax, and St. John's.

\section{POTENTIAL IMPACT OF A LONDON-BASED SRC}

Enhancing healthcare education and augmenting the treatment of underserved populations are two mechanisms through which an SRC can positively impact healthcare in London. ${ }^{5}$ Medical students volunteering in an SRC gain valuable experience independent of the official curriculum. This practical environment improves clinical knowledge and skills, provides collaborative experiences, fosters positive attitudes towards interprofessionalism, and develops comfort with in-need populations. Recent evidence indicates improved educational outcomes among medical students involved with SRCs. ${ }^{5-7}$ Students are given a chance to mature in their future role as a medical professional through autonomous clinical experience under the supervision of medical professionals. ${ }^{8}$ Students from educational backgrounds outside of the health sciences benefit from an improved understanding of the healthcare 
system and issues faced by underserved populations. ${ }^{9}$ SRCs also promote interest in primary care after graduation, specifically in targeting underserved populations. ${ }^{5}$ However, the benefits of the SRC approach are not isolated to student learning.

SRCs have been shown to improve specific health care outcomes in the general and underserved populations. The success rates of preventative medicine counselling, hyperlipidemia management, and depression screening have been shown to equate or exceed national averages in the United States. ${ }^{10-14}$ In particular, significant improvements in diabetic care in underserviced populations have been associated with treatment at SRCs. This includes indicators of diabetes control such as cholesterol level, HbAlc level, glycemic control, and blood pressure. ${ }^{15,16}$ Additionally, the SRC approach can improve diagnostic accuracy, promote greater compliance, decrease return visits, and increase patient satisfaction. ${ }^{17-20}$

A new interdisciplinary student group from the University of Western Ontario, Fanshawe College, and the University of Waterloo has taken the first steps towards establishing an SRC in London. The Alliance of Students Providing Interprofessional Resources and Education (ASPIRE) aims to help relieve the pressure on a healthcare system that is struggling to meet the needs of the community. As an initial step, ASPIRE recently completed a needs assessment, composed of a review of the healthcare needs and social determinants of health within the City of London; the city is home to 383,822 inhabitants as of 2016. The high incidence of mental health conditions (up to $22 \%$ in certain pockets of the city with lower socioeconomic status) ${ }^{21}$ and increasing HIV rates (5.9 to 9.0 cases per 100,000 between 2005 and 2015 compared to the provincial average decline of 7.4 to 5.5 cases per 100,000$)^{22}$ are two major concerns. Additionally, the three most prevalent chronic conditions presented to primary healthcare providers in communities across Canada, including London, are hypertension, arthritis, and chronic pain. ${ }^{23}$ These are all chronic conditions that professional students, including those from medicine, nursing, physiotherapy, and occupational therapy, can help manage; this can be done by creating personalized treatment plans, reviewing medications, and making appropriate referrals.

Major barriers to primary care identified in the assessment include distance to a primary care provider, the added financial burden of transportation to and from healthcare appointments, lost pay from time taken off work, and long wait times. ${ }^{21}$ This can be addressed by an SRC through extended hours of operation and through the provision of transportation support if funding and/or donations can be secured. Transitional barriers between provincial and federal funding and inadequate access to mental health services are additional limitations faced by Indigenous communities. Furthermore, immigrants may struggle to navigate a foreign health care system and to communicate through language barriers. These issues may be addressed by eliminating the need for a provincial health card when providing patient care at an SRC, and by holding workshops to inform newcomers about the intricacies of the Canadian healthcare system.
Not surprisingly, creating a student run clinic also comes with potential barriers. One of the biggest barriers to implementation is cost. This includes funding necessary for marketing and volunteer recruitment, clinical equipment, and the provision of supports such as nutritional meals and bus tickets. Avenues of funding that can be explored include grants, financial supports through partnering with educational institutions, community fundraising, and individual donations. However, all of these avenues do require large continuous efforts in order to maintain adequate funding. Ultimately, the current operation of several SRCs across Canada and the United States is a testament to the fact that these clinics can be successful with community efforts.

\section{ASPIRE HEALTH PROMOTION}

Although a London-based SRC is still in the works, ASPIRE has already embarked on a health promotion project serving the London community. Interdisciplinary teams of student volunteers have put together presentations on such topics as opioid addiction and overdose prevention, diabetic foot care, and smoking cessation. The first set of presentations is scheduled to take place in the community in mid to late November 2017. The hope is that the design and implementation of these presentations will serve as a stepping stone for ASPIRE to transition into a bigger role in health promotion and health advocacy in the city. Such exercises will also help develop the skill set of student volunteers and give them the opportunity to work interprofessionally early on in their careers.

\section{CONCLUSION}

More research still needs to be done on the outcomes of student run clinics, especially those in operation in Canada. Preliminary literature has demonstrated their utility to both students and community members. It is no secret that the Canadian healthcare system is strained, and that this strain is likely to increase with our aging population. Chronic health conditions, including pain syndromes, will continue to require a sizeable portion of healthcare resources. As such, an interdisciplinary student-led health team working under supervision has the potential to make a significant impact on the management of these conditions in a local setting.

\section{REFERENCES}

1. Holmqvist M, Courtney C, Meili R, et al. Student-run clinics: opportunities for interprofessional education and increasing social accountability. J Res Interprof Pract Educ. 2012;2(3):264-77.

2. CHIUS: Community Health Initiative by University Students [Internet]. Vancouver (BC): The University of British Columbia. About Us [cited 2018 Jan 28]. Available from: http://www.chius.ubc.ca.

3. Student Wellness Initiative Toward Community Health [Internet]. Saskatoon (SK): SWITCH; c2016. About; c2016 [cited 2018 Jan 28]. Available from: http://switchclinic.com/about/.

4. IMAGINE: students promoting health [Internet]. Toronto (ON): IMAGINE Student Clinic. About Us [cited 2018 Jan 28]. Available from: http://imagine-clinic.squarespace.com/about-us/.

5. Smith S, Thomas R, Cruz M, et al. Presence and characteristics of student-run free clinics in medical schools. JAMA. 2014 Dec 10;312(22):2407-10. 
6. Schutte T, Tichelaar J, Dekker R, et al. Learning in student-run clinics: a systematic review. Med Educ. 2015 Mar 1;49(3):249-63.

7. Seif G, Coker-Bolt P, Kraft S, et al. The development of clinical reasoning and interprofessional behaviors: service-learning at a student-run free clinic. J Interprof Care. 2014 Nov 1;28(6):559-64.

8. Teherani A. On autonomy in student-run clinics. Med Educ. 2015 Mar 1;49(3):238-9.

9. Shabbir S, Santos M. The role of prehealth student volunteers at a student-run free clinic in New York, United States. J Educ Eval Health Prof. 2015 Oct 30;12:49.

10. Butala N, Murk W, Horwitz L, et al. What is the quality of preventive care provided in a student-run free clinic? J Health Care Poor Underserved. 2012 Feb;23(1):414-24.

11. Liberman K, Meah Y, Chow A, et al. Quality of mental health care at a student-run clinic: care for the uninsured exceeds that of publicly and privately insured populations. J Community Health. 2011 Oct 1;36(5):733-40.

12. Rojas S, Smith S, Rojas S, et al. Longitudinal hyperlipidemia outcomes at three student-run free clinic sites. Fam Med. 2015 April;47(4):309-14.

13. Soltani M, Smith S, Beck E, et al. Universal depression screening, diagnosis, management, and outcomes at a student-run free clinic. Acad Psychiatry. 2015 Jun 1;39(3):259-66.

14. Zucker J, Lee J, Khokhar M, et al. Measuring and assessing preventive medicine services in a student-run free clinic. J Health Care Poor Underserved. 2013 Feb;24(1):344-58.

15. Gorrindo P, Peltz A, Ladner T, et al. Medical students as health educators at a student-run free clinic: improving the clinical outcomes of diabetic patients. Acad Med. 2014 Apr;89(4):625-31.

16. Smith S, Marrone L, Gomez A, et al. Clinical outcomes of diabetic patients at a student-run free clinic project. Fam Med. 2014 Mar 1;46(3):198-203.

17. Charon R. Narrative medicine: a model for empathy, reflection, profession, and trust. JAMA. 2001 Oct 17;286(15):1897-902.

18. Gross D, Zyzanski S, Cebul R, et al. Patient satisfaction with time spent with their physician. J Fam Pract. 1998;47(2):133.

19. Cepeda M, Chapman R., Miranda N, et al. Emotional disclosure through patient narrative may improve pain and well-being: results of a randomized controlled trial in patients with cancer pain. J Pain Symptom Manage. 2008 Jun;35(6):623-31.

20. Arntfield S, Slesar K, Dickson J, et al. Narrative medicine as a means of training medical students toward residency competencies. Patient Educ Couns. 2013 Jun 30;91(3):280-6.

21. Gilliland J, Clark A, Sibbald S, et al; Human Environments Analysis Laboratory, University of Western Ontario. Understanding health inequities and access to primary care in the South West LHIN. London: South West Local Health Integration Network: 2016. 286 p.

22. Middlesex-London Health Unit [Internet]. London (ON): MiddlesexLondon Health Unit. Health Unit to Address Local Public Health Emergency; [cited 2017 Nov 15]. Available from: https://www. healthunit.com/news/mlhu-to-address-local-public-healthemergency.

23. Canadian Institute for Health Information. A Snapshot of Health Care in Canada as Demonstrated by Top 10 Lists; 2011 [cited 2017 Nov 15]. Available from: https://secure.cihi.ca/free_products/Top10ReportENWeb.pdf.

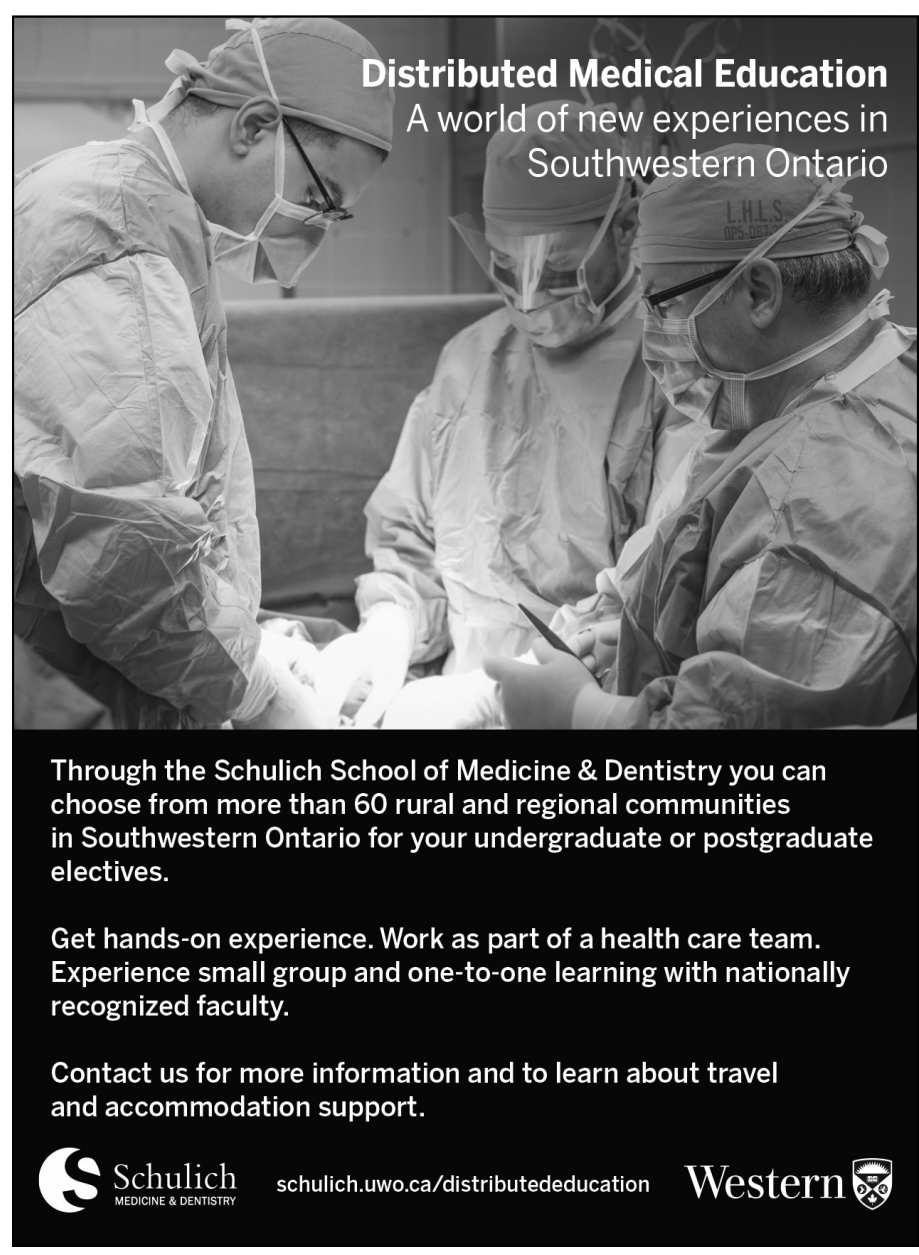

Get hands-on experience. Work as part of a health care team. Experience small group and one-to-one learning with nationally recognized faculty.

Contact us for more information and to learn about trave and accommodation support. 